\title{
Personal, Socio-economic, Psychological and Communication Characteristics of the Farmers about Climate Change in Dharwad district of Karnataka, India
}

\author{
Huchhappa Gondali ${ }^{1 *}$ and Dipak Kumar Bose ${ }^{2}$
}

Department of Agricultural Extension \& Communication, Sam Higginbottom University of Agriculture, Technology and Sciences, Naini, Allahabad-211 007, U.P., India

*Corresponding author

\section{Keywords}

Socio-economic,

Psychological,

Communication,

Climate change

Article Info

Accepted:

15 January 2019

Available Online:

10 February 2019

\section{A B S T R A C T}

The present study was conducted in Dharwad districts of Karnataka state during 2016-17. Descriptive research design was followed to assess the Personal, Socio-economic, Psychological and Communication Characteristics of the Farmers about Climate Change in Dharwad district of Karnataka with a sample of 120 respondents selected randomly. It shows that majority of the respondents $(51.67 \%)$ belonged to middle age group (36-50 years), whereas, $(29.17 \%)$ and $(19.16 \%)$ of them belonged to young age (18-35 years). To high school (15.83 \%), PUC (13.33\%) and Graduate (1.67\%) It implies that primary school groups have more perception and to initiate adaptation measures than middle school education and illiterate to climate change. It can be stated that more than 60 per cent of the respondents belonged under marginal and small farmers' category occupying 1 to 2 ha of land. Majority of the respondents were having medium annual income between (Rs. $34,000-51,000$ ), only about 13.33 per cent of the respondents belonged to low (up to Rs. $17,000 /-)$ annual income group category. Majority of the respondents had medium level $(53.33 \%)$ of contact with extension personnel, whereas, $(25.00 \%)$ and $(21.67 \%)$ of them had low and high. Almost all the respondents were having medium level $(52.5 \%)$ of use of mass media sources, whereas, $(26.67 \%)$ had high level and low level $(20.83 \%)$ use of mass media

\section{Introduction}

Agricultural operations are both directly and indirectly linked with climate change. Any alteration in the climatic parameters such as temperature and humidity which govern crop growth will have a direct impact on quantity of food produced. Indirect linkage pertains to catastrophic events such as flood and drought which are projected to multiply as a consequence of climate change leading to huge crop loss and leaving large patches of arable land unfit for cultivation and hence threatening food security. The net impact of food security will depend on the exposure to global environmental change and the capacity to cope with and recover from global environmental change. Climate change 
scenarios include higher temperatures, changes in precipitation, and higher atmospheric $\mathrm{CO}_{2}$ concentrations which may affect on agricultural operations as well as yield (both quality and quantity), growth rates, photosynthesis and transpiration rates, moisture availability, through changes of water use (irrigation) and agricultural inputs such as herbicides, insecticides and fertilizers etc. Environmental effects such as frequency and intensity of soil drainage leading to nitrogen leaching), soil erosion, land availability, reduction of crop diversity may also affect agricultural productivity. Nowadays, there is no region in every country where the impact of climate change is free from it. Declining rainfall and increasing temperature have had a significant negative impact on agricultural production and on food security (Parry et al., 2007). Scientific evidence shows that mean annual temperature has increased; and it is expected to further increase at a rate of $0.05{ }^{\circ} \mathrm{C}$ per decade, while rainfall has been erratic, decreasing on average at a rate of 5 to 10 per cent per annum, with annual anomalies mostly below normal. Adaptation to climate change refers to the adjustment in natural or human systems in response to actual or expected climatic stimuli or their effects to moderate harm or exploit beneficial opportunities.

\section{Materials and Methods}

The present investigation was conducted in Taluk Kundagol of Dharwad district which was selected based on depending upon extent of climate variation. The study covered 12 villages and 120 respondents who had more than 15 years of farming experience selected randomly. Data were collected using pretested interview schedule. The data on socioeconomic aspects like education, age, family type, land holding, occupation, income, mass media exposure were collected. The information was also gathered through focused group discussion and observation methods. The collected data were coded, tabulated, classified and analysed by both descriptive and inferential statistics were used

\section{Results and Discussion}

Personal, socio-economic, psychological and communication characteristics of the farmers about climate change

\section{Age wise distribution of the respondents}

The data in Table 1 depicts the personal and socio-economic characteristics of farmers. The results are presented under the following Table 1. Age of the head of household can be used to capture farming experience that might often mean better perception, access to information and knowledge. The data regarding age of the respondents are presented in Table 1. It shows that majority of the respondents $(51.67 \%)$ belonged to middle age group (36-50 years), whereas, (29.17\%) and $(19.16 \%)$ of them belonged to young age (18-35 years) and old age (more than 51 years), respectively. It can be concluded from data that most of the interviewed respondents were middle aged, while, around one third of them were belonged to young age followed by old aged. This reflected that respondents in study area were much experienced, which may help them to better adaptation against climate change. The findings are in line with results of Shiferaw and Holden (1998), Kumar and Narayana Gowda (1999).

Education wise distribution of the respondents

With regard to level of education, it can be observed from the Table 1 that, majority of the respondents were primary school (31.67 $\%)$ followed by Middle school (20.83\%), and illiterate $(16.67 \%)$, high school (15.83 $\%)$, PUC (13.33 \%), Graduate $(1.67 \%)$ 
respectively. To high school (15.83\%), PUC $(13.33 \%)$ and Graduate (1.67 \%) It implies that primary school groups have more perception and to initiate adaptation measures than middle school education and illiterate to climate change. In general climate change is a natural phenomena and anyone with a varying education level can perceive changes in their surroundings.

The findings revealed that most of the respondents of study area were primary school passed followed by middle and. high and higher secondary passed The above results are broadly supported by Norris and Batie (1987).

\section{Land holding wise distribution of the respondents}

It is observed from the Table 1 that the number of standard acres/hectares of land owned and cultivated by each respondent family was considered in determination of their size of land holding. The economic and social position of respondents in the society depends upon the size and fertility of the land in his/her possession.

The data in Table 1 clearly indicates that $(45.00 \%)$ of the respondents were possessing 1.1 to 2 ha of land and belonged to small farmers category, while, $(31.67 \%)$ and $(20.00$ $\%$ ) of the respondents belonged to marginal farmers (up to $1.0 \mathrm{ha}$ ) and medium farmers (2.1 to $4 \mathrm{ha}$ ) and category. Only (3.33\%) of the respondents were having more than 4 ha (big farmers) of land.

Thus, it can be stated that more than 60 per cent of the respondents belonged under marginal and small farmers' category occupying 1 to 2 ha of land. The above finding is in concurrence with the findings of Suresh (2004) and Karjagi (2006).

\section{Annual income}

The data pertaining to annual income of the respondents is given in Table 1 Majority of the respondents were having medium annual income between (Rs. 34,000-51,000) whereas, 35.00 per cent and followed by semi-medium annual income between (Rs. 17,000-34,000) 31.67 per cent were having high annual income (above Rs. 51,000/-) 20.00 per cent respondents, only about 13.33 per cent of the respondents belonged to low (up to Rs. 17,000/-) annual income group category. The findings are supported with the findings of Karjagi (2006), Knowler and Bradshaw (2007) and Binkadakatti (2008).

\section{Extension contact}

Table 1 depicted that the regards to contact of respondents with extension personnel, Majority of the respondents had medium level $(53.33 \%)$ of contact with extension personnel, whereas, $(25.00 \%)$ and $(21.67 \%)$ of them had low and high level of extension contact, respectively.

Extension contact of the respondents Regarding contact of farmers with extension personnel, it was observed from the Table majority of the meteorology department never contacted $(90.83 \%)$ with farmers and occasional $(3.33 \%)$ and regular $(5.83 \%)$ contact with farmers belonged to NGOs never contacted $(85.00 \%)$ with farmers and occasional $(5.83 \%)$ and regular $(9.17 \%)$ contact with farmers, followed by the ADA never contacted $(82.50 \%)$ and occasional $(11.67 \%)$ and regular $(5.83 \%)$, contact with farmer, bank officer never contacted (77.50 $\%)$ with farmers and occasional (16.67 \%) and regular $(5.83 \%)$ contact with farmers, extension officer never contacted $(75.83 \%)$ with farmers and occasional (18.33) and regular $(5.83 \%)$ contact with farmer, $\mathrm{AO}$ never contacted $(62.50 \%)$ with farmers and 
occasional $(28.33 \%)$ and regular $(9.17 \%)$ with contact, private agencies never contacted $(47.50 \%)$ with farmers and occasional (46.67 $\%)$ and regular $(5.83 \%)$ with contact farmers, Assistant Agril Officer never contacted (34.17 $\%)$ with farmers and occasional (50.83\%) and regular $(15.00 \%)$ contact with farmers,
Agricultural Assistant never contacted (18.33 $\%)$ with farmers and occasional $(65.83 \%)$ and regular $(15.83 \%)$ contact with farmers with respectively. Above findings are in line with the findings of Markad (1996), Dixit and Bhople (2001) and Rathod (2001).

Table.1 Personal, socio-economic, psychological and communication characteristics of the farmers about climate change

\begin{tabular}{|c|c|c|c|}
\hline Sr. no & Personal profile & Frequency & Percentage \\
\hline \multicolumn{4}{|l|}{ 1. Age } \\
\hline 1. & Young (Between 18 - 35 years) & 35 & 29.17 \\
\hline 2. & Middle (Between 36 - 50 years) & 62 & 51.67 \\
\hline 3. & Old (Above 51 years) & 23 & 19.16 \\
\hline \multicolumn{4}{|c|}{ 2. Education } \\
\hline 1. & Illiterate & 20 & 16.67 \\
\hline 2. & Primary school $\left(1^{\text {st }}\right.$ to $\left.4^{\text {th }}\right)$ & 38 & 31.67 \\
\hline 3. & Middle $\left(5^{\text {th }}-7^{\text {th }}\right)$ & 25 & 20.83 \\
\hline 4. & High school $\left(8^{\text {th }}-10^{\text {th }}\right)$ & 19 & 15.83 \\
\hline 5. & PUC & 16 & 13.33 \\
\hline 6. & Graduate and above & 2 & 1.67 \\
\hline \multicolumn{4}{|c|}{ 3. Land holding } \\
\hline 1. & Marginal farmers (Up to $1.0 \mathrm{ha}$ ) & 38 & 31.67 \\
\hline 2. & Small farmers (1.1 to $2.0 \mathrm{ha})$ & 54 & 45.00 \\
\hline 3. & Medium farmers (2. 1 to $4 \mathrm{ha}$ ) & 24 & 20.00 \\
\hline 4. & Big farmers (More than $4 \mathrm{ha}$ ) & 4 & 3.33 \\
\hline \multicolumn{4}{|c|}{ 4. Annual income } \\
\hline 1. & Low (up to Rs. 17,000/-) & 16 & 13.33 \\
\hline 2. & Medium (Rs. 34,000-51,000) & 42 & 35.00 \\
\hline 3. & Semi-medium (Rs. 17,000-34,000) & 38 & 31.67 \\
\hline 4. & High (above Rs. 51,000/-) & 24 & 20.00 \\
\hline \multicolumn{4}{|c|}{ 5. Extension contact } \\
\hline 1. & Low $(<12)$ & 30 & 25.00 \\
\hline 2. & Medium (12-14) & 64 & 53.33 \\
\hline 3. & High $(>14)$ & 26 & 21.67 \\
\hline \multicolumn{4}{|c|}{ 6. Mass media exposure } \\
\hline 1. & Low $(<17)$ & 25 & 20.83 \\
\hline 2. & Medium (17-21) & 63 & 52.50 \\
\hline 3. & High $(>21)$ & 32 & 26.67 \\
\hline
\end{tabular}




\section{Mass media exposure}

The respondents were asked about the mass media sources used by them and compiled results are presented in Table 1 Majority of the respondents $(41.67 \%),(25.00 \%)$ and $(24.17 \%)$, Entertainment, Agricultural programmes and Information/ News regularly watched television, whereas, (55.83\%), $(40.00 \%)$ and $(34.17 \%)$, Agricultural programmes, Entertainment and Information/ News came under occasional users of television. About (13.33\%) of the respondents were regular information news of news paper $(8.33 \%)$ of them Agriculture articles were occasional readers. Among the respondents regular listeners of radio were $(15.83 \%), \quad(10.83 \%)$ and (10.00), Agricultural programmes and Information/ News and Entertainment, while, (46.67\%), $(40.83 \%)$ and (30 \%), Information/News Agricultural programmes and Entertainment, were occasionally listened radio. Hardly (1.67 $\%)$ of the respondents read agriculture articles in, Information/News (1.67 \%). Whereas, about (20.00) and (12.50\%) of them read occasionally.

The mass media sources of respondents was determined and given in Table 1 almost all the respondents were having medium level $(52.5 \%)$ of use of mass media sources, whereas, $(26.67 \%)$ had high level and low level $(20.83 \%)$ use of mass media. Shashidhar (2003), Kumar (2004) and Nirban (2006) were also reported similar findings.

In conclusion, the medium level socioeconomic and perception of respondents so, to solve the problem of climate change at first we have to create awareness among the farmers by using mass media followed by interpersonal communication channel through trained extension agents. In addition, empowerment is crucial in enhancing farmers' awareness. It conclude that inadequate knowledge regarding effect of climate change on agriculture farmers and extension officers in the region, improving the knowledge and skills of extension personnel about climate change and adapted management strategies through training programmes should be taken up.

\section{References}

Aiken, Rob., (2009), Climate Change impacts on Crop Growth in the Central High Plains, Proceedings of the 21st Annual Central Plain Irrigation Conference, Pp. 14-15

Mahato A. (2014), Climate Change and its Impact on Agriculture, International Journal of Scientific and Research Publications, Volume 4, Issue 4.

Mall, R.K, Singh, R., Gupta, A., Srinivasan, G., and Rathore, L.S. (2012), Impact of Climate Change on Indian Agriculture: A Review, Pp. 446-448,472

Parry, M. L., Canziani, O. F., Palutikof, J. P., Van Der Linden, P. J. and Hanson C. E., (2007), Contribution of Working Group II to the Fourth Assessment Report of the Intergovernmental Panel on Climate Change. Cambridge University Press, Cambridge, U.K., p. 453.

Pasupalak, S., Pasupalak, S., (2009), Climate Change and Agriculture in Orissa, Orissa Review, 49-52

Priyadarshi, Nitish. (2009), "The Survival of Agriculture in a Destabilized Climate with special reference to India and its Jharkhand State."

Rai, Mangala. (2010), India's preparedness for food security in view of climate change, International Conference on Food Security and Climate Change in Dry Areas, p. 6-7

Wadood, A. and Kumari, P., (2011) Impact of Climate Change on Jharkhand Agriculture: Mitigation and Adoption, ISPRS Archives XXXVIII-8/W3 Workshop Proceedings: Impact of Climate Change on Agriculture, p. 207-210. 


\section{How to cite this article:}

Huchhappa Gondali and Dipak Kumar Bose. 2019. Personal, Socio-economic, Psychological and Communication Characteristics of the Farmers about Climate Change in Dharwad district of Karnataka, India. Int.J.Curr.Microbiol.App.Sci. 8(03): 1898-1903. doi: https://doi.org/10.20546/ijcmas.2019.803.225 